\title{
The Smart Ring Experience in L'Aquila (Italy): Integrating Smart Mobility Public Services with Air Quality Indexes
}

\author{
Maria-Gabriella Villani ${ }^{1, *}$, Fabio Cignini ${ }^{2}$, Fernando Ortenzi ${ }^{3}$, Domenico Suriano ${ }^{4}$ and \\ Mario Prato ${ }^{4}$ \\ ${ }^{1}$ ENEA, DTE-SEN-SCC, via Fermi 2749, 21027 Ispra VA, Italy; \\ ${ }^{2}$ Università La Sapienza, CTL, via della Polveriera, 48184 Roma, Italy; \\ ${ }^{3}$ ENEA, DTE-PCU-STMA, via Anguillarese 301, 00123 Roma, Italy; \\ ${ }^{4}$ ENEA, SSPT-PROMAS-MATAS, S.S. 7 "APPIA" KM 706, 72100 Brindisi, Italy. \\ * Author to whom correspondence should be addressed; E-Mail: mariagabriella.villani@enea.it; \\ Tel.: +39-0332-788249; Fax: +39-0332-788207.
}

Published: 11 November 2015

\begin{abstract}
This work presents the "City Dynamics and Smart Environment" activities of the Smart Ring project, a Smart City Paradigm, based on the integration of mobility urban services and environmental monitoring along a 4-5 km circular path, the "Smart Ring", around the historical centre of l'Aquila (Italy). We describe the integration of the mobility urban public service "Smartbus", an experimental on-demand public service electric bus with the multiparametric air quality low-cost electrochemical sensors NASUS IV, deployed to sample ambient air gas components $\left(\mathrm{NO}_{2}, \mathrm{CO}, \mathrm{SO}_{2}, \mathrm{H}_{2} \mathrm{~S}\right)$. For five days (28-29 August 2014 and 1-3 September 2014), NASUS IV was installed inside the Smartbus, and measured air quality parameters during the service. Data were collected and analysed on the base of an Air Quality index, which provides an insightful view of the status of the air quality potentially experienced by the Smartbus users, and indirectly, on the air quality along the Smart Ring track.
\end{abstract}

Keywords: L'Aquila; Smart Ring; Smartbus; urban environment; mobility on demand; low-cost electrochemical gas sensors; air quality index

\section{Introduction}

After the series of earthquakes in April 2009, which severely damaged the city of L'Aquila and the villages nearby, several projects were proposed to reconstruct the city. Among these, a 
collaborative agreement between ENEA and the L'Aquila local government was established in 2010 to help reconstructing the L'Aquila city centre according to a Smart City Paradigm (eg. [2]). The collaborative agreement produced the "Smart Ring" project, which aimed at the integration of mobility urban services, environmental monitoring and smart lighting along a 4-5 km circular path, the "Smart Ring", around the historical centre of L'Aquila ( see fig. 1a, and [14]).

This work reports the "City Dynamics and Smart Environment" activities of the Smart Ring project [14], which follow national and international projects such as RES-NOVAE [11], OPENSENSE [9], CITI-SENSE [4], and EVERY-AWARE [6]. These initiatives aim at presenting integrated technologies for energy efficiency use, and community-based sensing to raise environmental awareness. In the Smart Ring project, the multiparametric sensors NASUS IV (see [10], [16]) was deployed to sample ambient air gas components $\left(\mathrm{NO}_{2}, \mathrm{CO}, \mathrm{SO}_{2}, \mathrm{H}_{2} \mathrm{~S}\right)$, while being installed inside the mobility service Smartbus [13]. Thanks to the geographic positioning system embedded in the Smartbus control system, the ambient air inside the mobile service is sampled along the Smart Ring, as the Smartbus travelled along the track. Therefore, the Smartbus itself becomes a mobile sensor, which provides qualitative representations on the air status as experienced by the Smartbus commuters and, indirectly, of the ambient air on the Smart Ring. In this context, the proposed methodology may become a complementary tool to the already established air quality networks (eg. [5]).

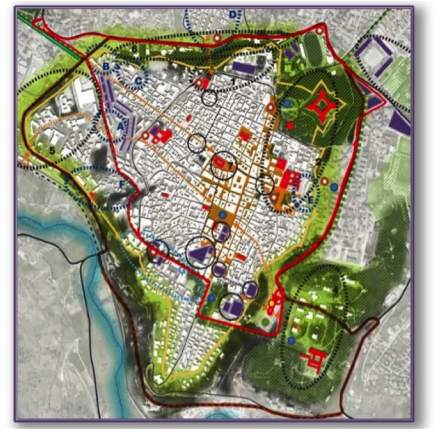

(a)

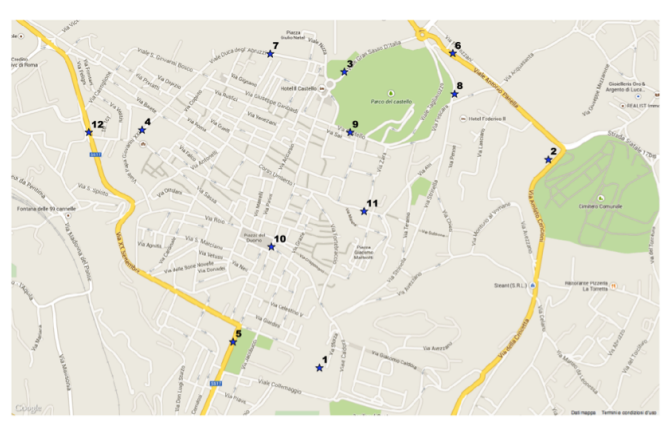

(b)

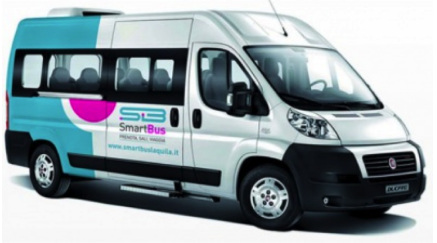

(c)

Figure 1. (a): the Smart Ring Map; (b): the Smartbus stops; (c): the Smartbus.

\section{Methodology}

\subsection{The Smartbus public service}

In the framework of a collaboration among AMA - Azienda Mobilità Aquilana, il Comune dell'Aquila, ENEA and DICEA CTL - Università di Roma La Sapienza, the experimental public transport service, named Smartbus ([13] and fig. 1c) was in operation for about six months from May 19 to October 31, 2014. Aim of the Smartbus service was to demonstrate the social, economical and quality service advantages of adopting a "on demand" electric bus service with respect to traditional public transport, characterised by thermally traction driven, and fixed time schedule and tracks. The service covered the mobility to and from the city centre, with about ten bus stops placed along the Smart Ring path (fig. 1b). A dedicated website [13] was set up to book the service, where day, time and departure 
and arrival bus stations had to be indicated. The ecological vehicle Iveco Daily (fig. 1c) was chosen for the bus. The vehicle could transport up to eight people and was provided with both thermal and electric traction. The Smartbus drivers were asked to use the electric traction particularly when driving along the way of the Smart Ring, accordingly to the load, the road slopes and the available electric charge. The electric traction was provided by fast rechargeable batteries, and the vehicle had an internal control system to monitor the geographical position, battery charge status, speed, and load/number of passengers. These vehicle parameters were sent in real time to a remote server while driving along the Smart Ring.

\subsection{The multiparametric sensor system NASUS IV}

The sensor system NASUS IV is described in details in [10] and in [16]. In brief, NASUS IV is a portable sensor system equipped with four low-cost electrochemical gas sensors $\left(\mathrm{NO}_{2}, \mathrm{CO}, \mathrm{SO}_{2}\right.$, e $\mathrm{H}_{2} \mathrm{~S}$ ) by Alphasense Ltd (UK) [1], one temperature sensor (LM35CZ) by National Semiconductor Co. (USA) [8], and one relative humidity sensor (HIH-3610 Series) by Honeywell (USA) [7]. The main technical characteristics of the low-cost sensors for air-quality monitoring are reported in the fig. 2. The low-cost set of four electrochemical gas sensors (shown in the fig. 2) is formed by four modules: main module, sensor module, wireless module and power module. The first three modules (PCBs) are packed in the same handheld case, but the power module is arranged in a separate case (fig. 2 see [16]). NASUS IV was installed in a PVC enclosure (IP65/66), where air comes to the NASUS IV sensor system throughout holes at the bottom of the enclosure. Generally speaking, this configuration is not ideal for accurate ambient air gas components samplings, as: i) sensors should be directly in contact with the air to sample, and ii) it is not advisable to use PVC enclosures for gas components sampling, particularly for ozone and nitrogen oxides compounds (Standard methods as referenced in EU DIR 2008/50/EC). This was proven also in the study [15]. However, since we are looking at representations of likely air polluted hot spots, more than having accurate data satisfying the data quality objective prescribed by the EU DIR 2008/50/EC (in Italy [5]), we investigated if NASUS IV could be used for our purpose, given this architecture.

\begin{tabular}{|l|l|l|}
\hline Sensors & Model e factory & Operativity range \\
\hline $\mathrm{NO}_{2}$ & $\mathrm{NO}_{2} \mathrm{~A} 1-\mathrm{A} 3$ Alphasense Ltd (UK) & $0-20(\mathrm{ppm})$ \\
\hline $\mathrm{CO}$ & $\mathrm{COCX}-\mathrm{A} 3$ Alphasense Ltd (UK) & $0-1000(\mathrm{ppm})$ \\
\hline $\mathrm{SO}_{2}$ & $\mathrm{SO}_{2} \mathrm{AF}-\mathrm{A} 3$ Alphasense Ltd (UK) & $0-20(\mathrm{ppm})$ \\
\hline $\mathrm{H}_{2} \mathrm{~S}$ & $\mathrm{H}_{2}$ SA1-A3Alphasense Ltd (UK) & $0-20(\mathrm{ppm})$ \\
\hline Temperature & LM35CZ National Semiconductors Co. (USA) & $-55 \mathrm{C} \mathrm{deg}+150 \mathrm{C}$ deg \\
\hline Relative humidity & $\mathrm{HIH}-3610$ Series Honeywell (USA) & $0-100 \% \mathrm{RH}$ \\
\hline
\end{tabular}

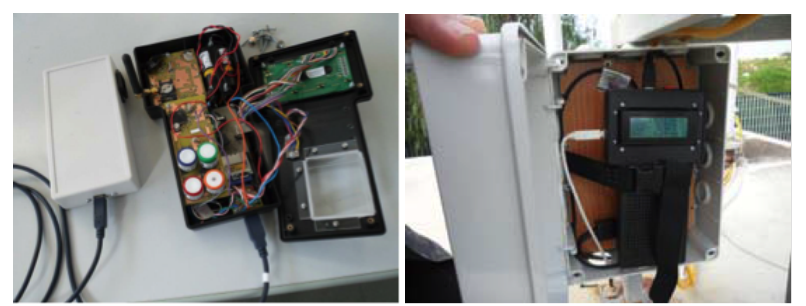

Figure 2. The NASUS IV multisensor system: characteristics and architecture.

\subsection{The Air Quality Index AQI}

The air quality index proposed by [10] was used to represent the air quality status. The air quality index, AQI, was calculated as the percent ratio $($ ratio $\times 100)$ of the measured concentration with respect to a reference level, chosen among the values prescribed by the air quality legislation [5]: for $\mathrm{CO}, 8$ ppm; $\mathrm{NO}_{2}, 100 \mathrm{ppb} ; \mathrm{H}_{2} \mathrm{~S}, 90 \mathrm{ppb}$; and for $\mathrm{SO}_{2}, 130 \mathrm{ppb}$. According to the AQI value, five categories 
were defined to indicate the air quality status (tab. 1). A maximum AQI index, AQI $I_{\max }$, is calculated considering the highest value among the AQIs calculated for each gas component $\left(\mathrm{AQI}_{\mathrm{NO}_{2}}, \mathrm{AQI}_{\mathrm{SO}_{2}}\right.$, $\left.\mathrm{AQI}_{H_{2} S}, \mathrm{AQI}_{C O}\right)$, e.g. [3].

Table 1. AQI values in relation to the air quality status.

\begin{tabular}{|l|l|l|}
\hline AQI values & Air quality status & Colours \\
\hline$<33$ & Excellent & Blue \\
\hline $34-66$ & Good & Green \\
\hline $67-99$ & Moderate & Yellow \\
\hline $100-150$ & Bad & Red \\
\hline$>150$ & Worse & Violet \\
\hline
\end{tabular}

\subsection{Experimental Campaign and Data Analyses}

During the Smartbus experimental public service, the multiparametric system NASUS IV was installed inside the Smartbus and operated for five days, on the $28^{t h}, 29^{t h}$ August, and the $1^{s t}$, $2^{\text {nd }}, 3^{\text {rd }}$ September 2014. The two acquisition systems were independent. The Smartbus on-board computer system recorded data whenever the bus was in operation, generally from 07:00 to 21:00 LT (time resolution of $1 \mathrm{~s}$ ). The system NASUS IV operated continuously (time resolution of $4 \mathrm{~s}$ ) for the whole measurement campaign, and data were stored on a memory card. The tab. 2 reports the parameters collected from the two systems. Before starting the measurement campaign, the internal clocks of the SmartBus and NASUS IV were synchronised, and assumed to provide the same time for the whole campaign. This operation was essential in order to match data from NASUS IV and the Smartbus afterwards. After the experimental campaign, data were checked for quality analyses, and later imported into a PostgreSQL database. From here, data were analysed and visualised using R-Cran and QuantumGIS softwares.

Table 2. Main parameters measured by the Smartbus and NASUS IV.

\begin{tabular}{|c|c|}
\hline Smartbus & NASUS IV \\
\hline $\begin{array}{l}\text { Datetime } \\
\text { (timestamp) }\end{array}$ & $\begin{array}{l}\text { Datetime } \\
\text { (timestamp) }\end{array}$ \\
\hline $\begin{array}{l}\text { Latitude } \\
\text { (deg) }\end{array}$ & $\begin{array}{l}\mathrm{NO}_{2} \\
(\mathrm{ppm})\end{array}$ \\
\hline $\begin{array}{l}\text { Longitude } \\
(\mathrm{deg})\end{array}$ & $\begin{array}{l}\mathrm{SO}_{2} \\
(\mathrm{ppm})\end{array}$ \\
\hline $\begin{array}{l}\text { Altitude } \\
(\mathrm{m})\end{array}$ & $\begin{array}{l}\mathrm{H}_{2} \mathrm{~S} \\
(\mathrm{ppm})\end{array}$ \\
\hline $\begin{array}{l}\text { Speed } \\
(\mathrm{km} / \mathrm{h})\end{array}$ & $\begin{array}{l}\mathrm{CO} \\
(\mathrm{ppm})\end{array}$ \\
\hline \multirow[t]{2}{*}{$\begin{array}{l}\text { Ambient air Temperature } \\
(\mathrm{C} \text { deg })\end{array}$} & $\begin{array}{l}\text { Temperature } \\
(\mathrm{C} \text { deg })\end{array}$ \\
\hline & Relative humidity (\%) \\
\hline
\end{tabular}

\section{Results and Discussion}

The AQI for each gas component and the AQI ${ }_{\max }$ were calculated. The $A Q I_{\max }$ was then plotted on map and statistically analysed (fig. 3). The main following features could be identified. 
As a result of the "on-demand" service, the path followed during the Smartbus service did change during the five days. Measurements were be too limited for data analyses over specific tracks.

Data were discontinuously distributed over time, with several missing data whenever the Smartbus was at rest. From this, the most frequented bus stops were identified.

Over the Smart Ring, accounting for $85 \%$ of data, Smartbus users experienced generally good air quality status, as measurements reported mean $\mathrm{AQI} \mathrm{I}_{\max }$ values less then 68 (fig. 3).

On the peripheral roads, where about $15 \%$ of data were collected, the $A Q I_{\text {max }}$ values were generally higher likely as a results of i) major traffic, ii) presence of tunnels, and iii) the Smartbus function mode set to gasoline.

The analyses conducted over the Smart Ring showed that, over the five days of campaign, $\mathrm{NO}_{2}$ provided the highest values for AQI (mean value of 44), followed by $\mathrm{H}_{2} \mathrm{~S}$ (AQI mean value of 19), $\mathrm{SO}_{2}$ (AQI mean value of 13), and $\mathrm{CO}$ (AQI mean value of 5).

\begin{tabular}{|l|l|l|l|l|l|l|l|}
\hline AQI & & $\mathbf{2 8 . 0 8 . 1 4}$ & $\mathbf{2 9 . 0 8 . 1 4}$ & $\mathbf{0 1 . 0 9 . 1 4}$ & $\mathbf{0 2 . 0 9 . 1 4}$ & $\mathbf{0 3 . 0 9 . 1 4}$ & $\mathbf{5}$-days \\
& & $\mathrm{n} .3427$ & $\mathrm{n} .3266$ & $\mathrm{n} .3463$ & $\mathrm{n} .3492$ & $\mathrm{n} .2393$ & n.16041 \\
\hline $\mathrm{NO}_{2}$ & Mean & 32.0 & 43.0 & 41.9 & 44.0 & 67.0 & 44.0 \\
& $($ Std) & $(17.0)$ & $(16.0)$ & $(11.5)$ & $(16.0)$ & $(26.0)$ & $(20.0)$ \\
& $90 \%$ & 61.1 & 64.0 & 55.1 & 64.4 & 106.5 & 69.0 \\
& $($ Min-max) & $(0-106.0)$ & $(16.0-116.0)$ & $(12.4-81.1)$ & $(7.0-99.0)$ & $(31.0-143.0)$ & $(0-143.0)$ \\
\hline $\mathrm{SO}_{2}$ & Mean & 27.0 & 32.0 & 0 & 1.3 & 0 & 13.0 \\
& $($ Std) & $(19.0)$ & $(27.0)$ & 0 & $(3.3)$ & 0 & $(18.0)$ \\
& $90 \%$ & 53.4 & 74.1 & 0 & 6.4 & 0 & 45.6 \\
& $($ Min-max $)$ & $(0-73.0)$ & $(0-91.0)$ & 0 & $(0-17.8)$ & 0 & $(0-91.0)$ \\
\hline $\mathrm{H}_{2} \mathrm{~S}$ & Mean & 36.0 & 31.0 & 3.3 & 18.0 & 3.2 & 19.0 \\
& $($ Std) & $(14.0)$ & $(11.0)$ & $(4.1)$ & $(20.0)$ & $(3.6)$ & $(18.0)$ \\
& $90 \%$ & 52.3 & 43.4 & 10.1 & 39.4 & 8.8 & 43.7 \\
& $($ Min-max) & $(0-61.0)$ & $(0-56.0)$ & $(0-15.2)$ & $(0-99.0)$ & $(0-11.0)$ & $(0-99.0)$ \\
\hline $\mathrm{CO}$ & Mean & 2.7 & 6.4 & 2.4 & 8.9 & 1.3 & 5.0 \\
& $($ Std) & $(4.1)$ & $(6.9)$ & $(2.2)$ & $(9.1)$ & $(1.7)$ & $(60.0)$ \\
& $90 \%$ & 8.6 & 16.6 & 4.9 & 16.5 & 3.8 & 10.7 \\
& $($ Min-max $)$ & $(0-15.7)$ & $(0-27.2)$ & $(0-9.4)$ & $(0-47.0)$ & $(0-6.2)$ & $(0-47.0)$ \\
\hline MAX & Mean & 44.0 & 54.0 & 41.9 & 46.6 & 68.0 & 50.0 \\
& $($ Std) & $(15.0)$ & $(16.0)$ & $(11.5)$ & $(18.6)$ & $(26.0)$ & $(19.0)$ \\
& $90 \%$ & 63.5 & 77.3 & 55.1 & 73.1 & 143.3 & 143.3 \\
& (Min-max) & $(2.0-106.0)$ & $(27.0-116.0)$ & $(12.4-81.1)$ & $(7.4-99.3)$ & $(31.0-143.0)$ & $(2.0-143.0)$ \\
\hline
\end{tabular}

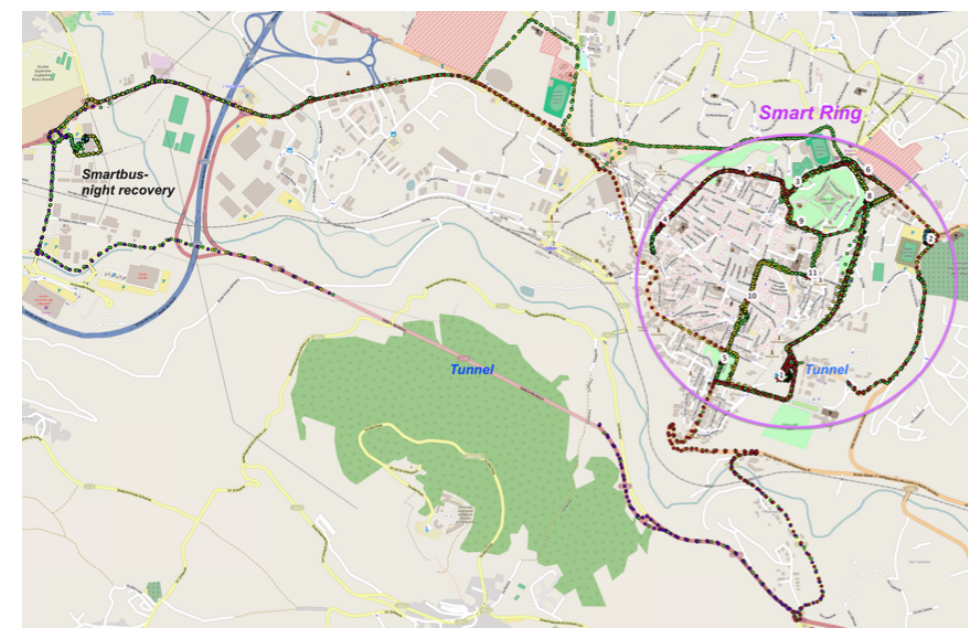

Figure 3. Left: Data analyses over the Smart Ring. Right: Picture of the $A Q I_{\text {max }}$ during the measurement campaign.

\section{Conclusions and Outlook}

We proved that our system can provide data at high temporal and spatial resolutions, covering geographical areas where air quality measurements may not be generally available. In our measurement campaign, the data collected were relatively limited. A larger number of data is required in order to have a more sounded statistics and to better identify spatial and temporal trends of the air quality indexes along the Smart Ring. To this aim, a larger number of "Smart" buses equipped with multiparametric sensors are needed to cover several areas of the city centre simultaneously. Further developments of the Smart Ring experience would be directed to: i) improve the NASUS IV system (sensor system enclosure material, sensor technologies and air flow exchange architecture); ii) a unique acquisition system infrastructure to manage data from different sensors platforms simultaneously; iii) establishment of a calibration procedure to better characterise air quality sensors data with referenced values; iv) detailed comparisons and correlation between the air experienced inside the vehicle and the outdoor ambient air. 


\section{Acknowledgments}

The project was funded under the strategic research programme CNR/ENEA from MIUR (legge 23 dicembre 2009, n. 191, Legge finanziaria 2010, art. 2 comma 44; legge 13 dicembre 2010, n. 220, Legge di stabilità 2011).

\section{Conflicts of Interest}

The authors declare no conflict of interest.

\section{References}

1. Alphasense Ltd (UK) http://www.alphasense.com. Accessed on 14.08.2014.

2. Annunziato M. and Meloni C. City 2.0, Il futuro delle città, la sfida delle smart cities tra opportunità e necessità. http://www.festivaldellenergia.it/ebook/smart_city.pdf. Accessed on 02.10.2015.

3. Arpa Emilia Romagna. http://www.arpa.emr.it. Accessed on 02.10.2015.

4. CITI-SENSE, European Project of the 7th Framework Programme. Development of Sensor-based Citizens Observatory Community for Improving Quality of Life in Cities. http://www.citi-sense.eu. Accessed on 02.10.2015.

5. Decreto Legislativo 155/2010: Attuazione della direttiva 2008/50/CE relativa alla qualità dell' aria ambiente e per un'aria più pulita in Europa. (10G0177) (GU n.216 del 15-9-2010 - Suppl. Ordinario n. 217). http://www.normattiva.it/uri-res/N2Ls?urn:nir:stato:decreto.legislativo:2010; 155. Accessed on 02.10.2015.

6. EVERY-AWARE, European Project of the $7^{\text {th }}$ Framework programme, Enhance Environmental Awareness through Social Information Technologies. http://www.everyaware.eu. Accessed on 02.10.2015.

7. Honeywell (USA). http://www.honeywell.com/sensing. Accessed on 02.10.2015.

8. National Semiconductor (USA). http://www.national.com. Accessed on 02.10.2015.

9. OPENSENSE Sensing the air we breath http://opensense.epfl.ch/wiki/index.php/OpenSense_2. Accessed on 13.10.2015.

10. Penza M., Suriano D., Villani M.G., Spinelle L., Gerboles M., 2014, Towards Air Quality Indices in Smart Cities by Calibrated Low-Cost Sensors Applied to Networks, Sensors, 2014 IEEE, pp 2012-2017, DOI: 10.1109/ICSENS.2014.6985429

11. National Italian Project RES-NOVAE: Networks, Edifici, strade: Nuove Sfide per l'Ambiente e l'Energia. http://resnovae-unical.it. Accessed on 02.10.2015.

12. Shinyei Technology Co. Ltd (Japan). http://www.shinyei.co.jp/stc/eng. Accessed on 02.10.2015.

13. Smartbus initiative in L'Aquila. http://www.smartbuslaquila.it. Accessed on 20.01.2015.

14. Smart Ring Project in L'Aquila. http://www.uttei.enea.it/tecnologie-per-le-smart-cities/progetti/ progetto-city-2.0. Accessed on 02.10.2015.

15. Spinelle L., Villani M. G., Suriano D., Penza M., Gerboles M., Aleixandre M., Calibration of a Cluster of Low-Cost Sensors for the Measurement of Air Pullution in Ambient Air, Poster presented at MACPoll final conference, Metrology for Chemical Pollutants in Air, Delft (NL) 13-14 May 2014. 
16. Suriano D., Penza M., Cassano G., Villani M. G., Assennato G., Nocioni A., Development of a Portable Sensor System for Air Quality Monitoring. COST Action TD1105 EuNetAir, $2^{\text {nd }}$ International Workshop EuNetAir, Brindisi (Italy), 25-26 March 2014.

(c) 2015 by the authors; licensee MDPI, Basel, Switzerland. This article is an open access article distributed under the terms and conditions of the Creative Commons Attribution license (http://creativecommons.org/licenses/by/4.0/). 